\title{
RFID Control System for the Embarkation/Disembarkation of Passengers and Vehicles on/from Ferries
}

\author{
Toni Mišković, Pančo Ristov, Zvonko Markić
}

Radio-frequency identification (RFID) is a technology which provides automatic identification and real time data acquisition capabilities without requiring additional human resources. This paper presents a control system for the embarkation/ disembarkation of passengers and vehicles on/from ferries, supported by RFID technology. A basic model of a RFID control system is developed to introduce the notion of RFID as a technology capable of access control with certain technical constraints. The ticket check-in process, made automatic by simple entry of a tag into the field of a RFID reader, increases the flow of passengers and vehicles, reduces port congestion, eliminates the possibility of boarding the wrong (by destination) ferry, and significantly reduces the number of cash payments.

\section{KEY WORDS}

$\sim$ RFID

$\sim$ Tag

$\sim$ Reader

$\sim$ Business process

$\sim$ Access control

$\sim$ Port

$\sim$ Ferry

\section{INTRODUCTION}

Radio-frequency identification is a technology based on automatic identification and data collection. Nowadays, companies introduce new technologies to reduce costs, improve efficiency or simply to raise product or service quality and ensure market competitiveness.

RFID technology has become an integral part of everyday life, finding its application in a wide variety of areas, e.g.: as a transportation payment tool (electronic tolls and public transportation), in libraries (speedsupbookborrowing and return), the automotive industry (smart keyless ignition systems), spare parts monitoring (life cycle supervision), animal identification and monitoring (pet owner identification), e-passports, human implantation (supervision of criminals, coordination and monitoring of army and personal identification), restricted access to buildings or rooms within buildings, contactless payment systems, asset tracking, warehouse management and logistics, supply chain product tracking, product safety and tracking of the movement of raw materials and parts within factories, counterfeit product detection, automatic vehicle identification (AVI) systems, railroad car tracking, luggage tracking at airport, military industry, maritime industry (container monitoring and tracking, access control) (Narsoo et al., 2009; Günther et al, 2008; Hansen et al., 2006). In this age of various "smart" devices, such as "smart" TVs, mobile phones, home appliances and even "smart" houses, one cannot help but wonder whether it is possible to create a "smart" ship? Can RFID technology contribute to the development of the next/new generation of ships? 
Maritime processes, including port processes such as sale and control of passenger tickets in maritime transport, are increasingly reaping the benefits of RFID technology, especially safety and unique identification. Norwegian ship operator Fjord Line uses RFID technology to monitor and control ticketing and cabin access on one of its ferries (MS Stavangerford with the capacity of 1,500 passengers and 600 vehicles), and is planning to expand the technology's use to its other ferries and other onboard services, such as at restaurants (Swedberg, 2013).

In December 2009, a RFID-based waterproof wristband tag was introduced at a $361 \mathrm{~m}$ long cruise ship Oasis of the Seas, owned by the Royal Caribbean company. RFID technology shortened queues at boarding and the initial 1,000 tags enabled the identification of passengers aboard the cruise ship capable of catering for approximately 6,300 passengers and 2,394 crew members and staff at full capacity (Swedberg, 2010).

In 2014, the Royal Caribbean company continued with its good practice of RFID technology use by introducing it to its 347 $\mathrm{m}$ long cruise ship Quantum of the Seas, shown in Figure 1. Before boarding, passengers purchase a waterproof RFID wristband tag worth $\$ 2$, using a $13,56 \mathrm{MHz}$ frequency in compliance with the ISO 14443 standard. The passenger embarkation check-in process (taking a maximum of 10 minutes) is performed manually by staff members using a MC9190-Z handheld RFID reader manufactured by Zebra Technologies, while all luggage is marked by a passive UHF RFID tag. The development of a smart phone application for personal luggage tracking from the "loading" to "delivered into cabin" status has proved its worth since it allows passengers to enjoy the facilities and services of the ship while waiting for the notification that their luggage has finally been delivered to their cabin. The ship's special attraction is the robotic bar where two robots, calibrated to millimeter accuracy, serve drinks within 60 seconds without the presence of a waiter. The wristband RFID tag identifies the users and alcoholic beverages may only be served if the automatically identified person is over 21 years of age. All service payments are cash-free, made by deducting the appropriate amounts from the funds paid to the wristband RFID tag, which also serves as a replacement for the traditional cabin key. RFID technology likewise contributes to safety by enabling the identification and tracking of people during security drills and procedures - a matter of utmost importance onboard a ship with the capacity of 4,900 passengers and 1,500 crew members and staff. The Royal Caribbean installed approximately 280 RFID readers onboard the Quantum of the Seas as part of a ship-wide transaction and identification network. RFID technology is used to allow free and relaxed movement of family and friends, while simultaneously giving a clear insight into their whereabouts at all times. According to Bill Martin, the Royal Caribbean plans to continue with the good practice of RFID technology use by introducing it to its cruise ship Ovation of the Seas by the spring of 2016 (Swedberg, 2014).

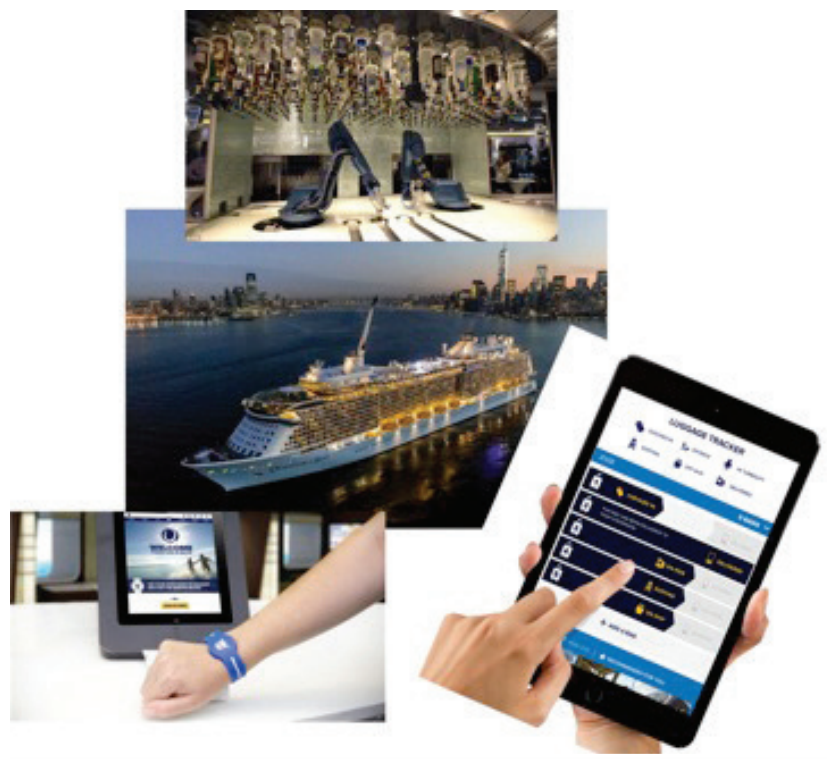

Figure 1.

Usage of RFID technology on the Quantum of the Seas cruise ship during embarkation and in other RFID-supported onboard services.

\section{OVERVIEW OF THE RFID SYSTEM}

RFID technology is based on the transmission of data via radio frequency or radio waves. RFID technology can be defined as technology that incorporates the use of electromagnetic or electrostatic feedback in the radio frequency part of the electromagnetic spectrum to uniquely identify a person, animal or an object. RFID technology is based on a system consisting of three main components: tag, reader and middleware. Technological advancement made possible the development of broader-range tags than in the first half of the twentieth century. The aim of any RFID system is to convert information about each unique product into digital format which allows further processing and storage in a database, simply and rapidly.

Figure 2 is a simplified model of a RFID system, its main components and their interconnections. The RFID tag, located on or inside a designated object, is irradiated with radio waves emitted by the reader. The tag then uses its integrated antenna to convert the received signal into electric energy it needs to perform its duty. Simultaneously, the tag sends the content of its memory (information about an identified object) to a RFID reader. The use of special anti-collision algorithms to prevent interference allows the reader to simultaneously read a large number of tags, with the number and speed of reading depending on the type of the reader and the tags, as well as on the range of the RFID reader's field. RFID reader converts received information into digital 




A) Collision between tags



B) Collision between readers

Figure 3.

Various collision occurrences.

Conflict between readers occurs when two readers are installed in such proximity to each other that the ranges of their electromagnetic fields intersect and overlap, if a tag appears in that section of their fields, the tag will simultaneously communicate with both readers without knowledge of collision. The tag will immediately react to the request of both readers since it is incapable of recognizing the reader intersection zone. Collision between tags occurs when more than one tag appears in the range of a reader's field, simultaneously attempting to forward their information to the reader. This is the most commonly encountered collision scenario. One must not disregard the fact that the tags are incapable of direct mutual communication,

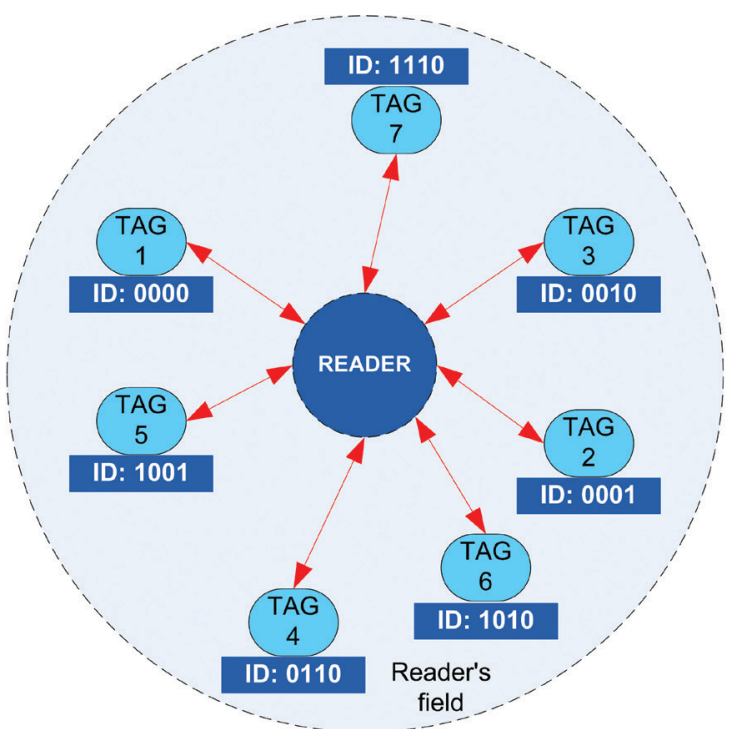

Collision between tags

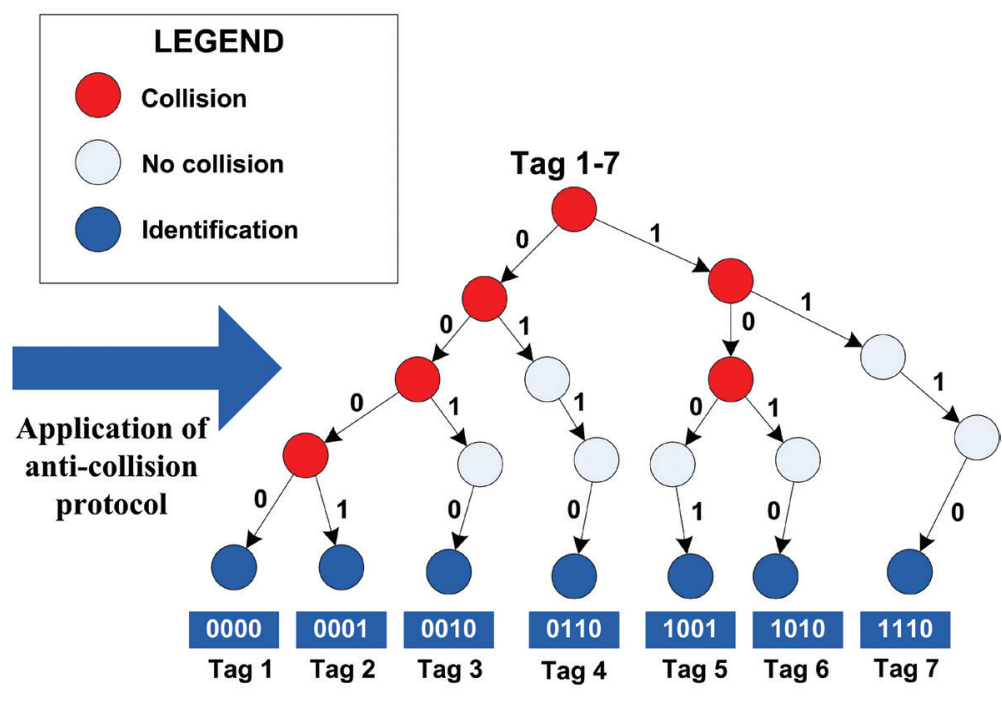

Figure 4.

Application of anti-collision procedure between tags. 
since communication unfolds exclusively through the reader, i.e. the tags can not recognize the simultaneous existence of other tags in the reader's field. When implementing an anti-collision protocol, one must bear in mind that the maximum number of tags simultaneously present in the field need not be fixed and known in advance and that the anti-collision system must be scalable at this point. Collision between tags is possible even if a single user has two or more different RFID tags (smart cards) on him/her (e.g. several contactless cards for paying for various forms of public transportation), in which case the RFID system must successfully charge the appropriate card without noticeable delay.

The following paragraph will provide an example of resolution of collision between tags in order to get an insight into what happens when several passengers or vehicles simultaneously approach the ferry and contact the same

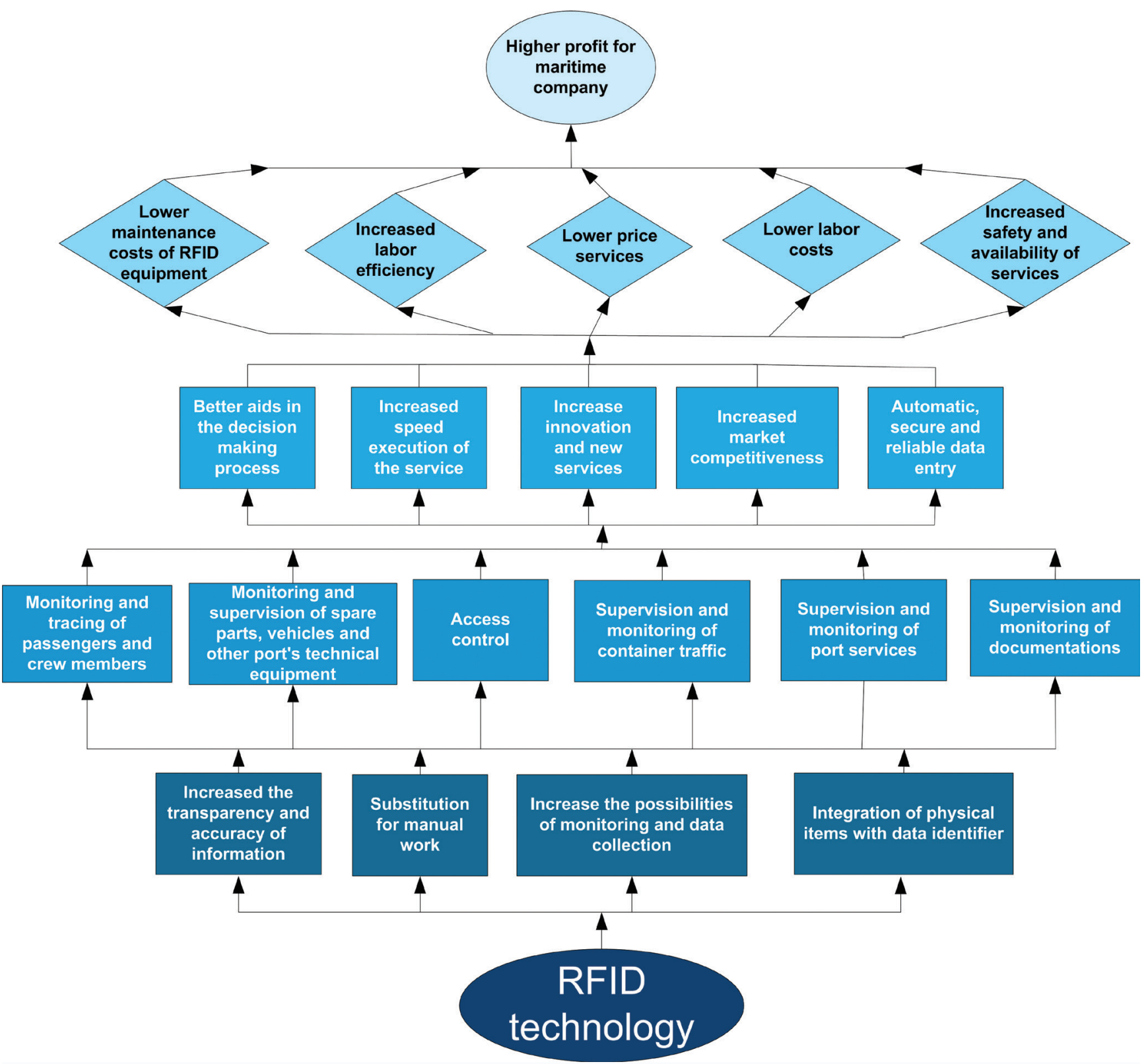

Figure 5.

Economic impact and developments stemming from the use of RFID technology in ports. 
RFID reader. The issue of collision occurring in the event of simultaneous presence of numerous tags in the interrogation zone of a single reader and the application of binary tree anticollision procedure is shown in Figure 4.

The above anti-collision procedure is based on a binary tree founded on a recursive function. The root of the binary tree is common to all tag IDs, and each tree node contains an additional component of tag ID information, while the final leaf of each branch of the tree represents a specifically identified tag ID. The characteristics of inheritance and parent-child relationship are also applied. The binary tree-run anti-collision algorithm is based on the principle of a reader's inquiry on the tag ID. In each round, the reader transmits a parity bit ( 0 or 1 ) to tags, and only tags containing the prefix which matches the parity bit, respond. When collision occurs, the reader sorts the tags by applying the principle of control bits ( 0 or 1 ) and repeats the process until resolution, i.e. only tags involved in the collision participate in further iterations. This procedure is repeated until only one tag responds to the reader's inquiry or until every branch of the binary tree is checked, i.e. until all tags are identified. The scalability of the binary tree anti-collision procedure is manifested in recursion and iteration (Usama and Mohammed, 2011).

\section{APPLICATION OF RFID TECHNOLOGY IN PORT PROCESSES}

Figure 5 illustrates the economic impact, developments and application areas of RFID technology in port processes. Numerous factors make RFID technology the best choice for port process automation.

RFID technology is suitable for monitoring and supervision of spare parts, vehicles and technical equipment, access control (control of authorized and unauthorized movement), supervision and monitoring of container handling, supervision and monitoring of port services, tracing passengers and crew members and monitoring documents. Monitoring and supervision of onboard services (such as cabin access control or restaurant services) may also be improved by implementing RFID technology. Individual and customized services (breakfast, Internet access, cocktails, etc.) can be offered via RFID-based prepaid solutions, eliminating the need for vouchers (additional discounts for frequent travelers are becoming available). All these factors contribute to the reduction of human resources, paperwork and manual labor, accelerate the execution of business processes and increase the financial profits of maritime companies.

In 2013, the RFID market was worth 8.8 billion dollars, 9.5 billion dollars in 2014 and 10.1 billion dollars in 2015. This includes tags, readers, and software for RFID cards, labels and other forms of tags. The market's value is expected to reach 13.2 billion dollars by 2020 (Research reports and subscriptions, 2015).
Globalization contributed to a series of transformations in all lines of business. These changes have an impact on ports, as important links in the transportation of goods on the door-todoor principle. Port authorities are encouraged to optimize their business processes to remain competitive on the services market and especially in the container transportation business, which renders cost reduction and port process automation a necessity.

Port authorities are trying to increase efficiency by effective management of all business processes in the port, and directing all funds towards control, transparency, availability of services, automation and security. To meet their goals and fulfil their mission, port authorities use modern information and communication systems based on the latest technologies (Ristov and Mrvica, 2011).

RFID technology enables item identification at great distances, automatically enters data in real time, facilitates and accelerates access to data and ensures the transfer of data to the port's information and communication system. The benefits of using RFID technology in comparison to other technologies are: adaptability to working conditions (moisture, dirt, high temperature, mechanical resistance), long lifetime (standards proscribe a 10-year duration of RFID media with a minimum of 100,000 readings), secure data storage on tags, the favorable price of RFID elements, $99.5-100 \%$ reading accuracy at first scan etc.

The mean time between failures (MTBF) of a RFID system consisting of 1,000 readers can be calculated as (1):

$$
M T B F=\frac{l_{t}}{\sum_{t=1}^{N} q_{t} \times f_{t}}
$$

where:

- $\quad \mathrm{N}-$ is the time interval,

- I - lifetime,

- $\quad \mathrm{t}$ - tag detected by a reader,

- q-quantity of components (readers in this case),

- $f$ - failure rate associated with a component.

The following example shows how to calculate the MTBF for the RFID reader by using the equation (1). RFID readers are the only components of the system. In a system with a total of 1,000 RFID readers operating over 100 hours, 10 RFID readers are expected to fail. If equation (1) is applied, MTBF for a RFID system consisting of 1,000 readers can be calculated as follows (2):

$M T B F=\frac{1000 \times 100}{\sum_{t=1}^{1} 1 \times 10}=\frac{100000}{10}=10000=10^{4}$ 
The obtained MTBF hours should be divided by 24 to arrive at the number of days the RFID system will statistically operate as planned between failures. Clearly, the final MTBF for a RFID system consisting of 1,000 readers is 416 days. MTBF is a quantitative indicator of repairable systems, essential for modern technical systems. The sample of 1,000 strategically placed RFID readers is more than sufficient for the next generation of smart ships to create identification networks capable of locating any person onboard at any moment.
3.1. Monitoring the Embarkation of Passengers and Vehicles on Ferries

Owing to its many benefits, RFID technology can be used to automate the embarkation of passengers and vehicles on ferries. Figure 6 illustrates a RFID-based access control system used for the embarkation of passengers and vehicles.
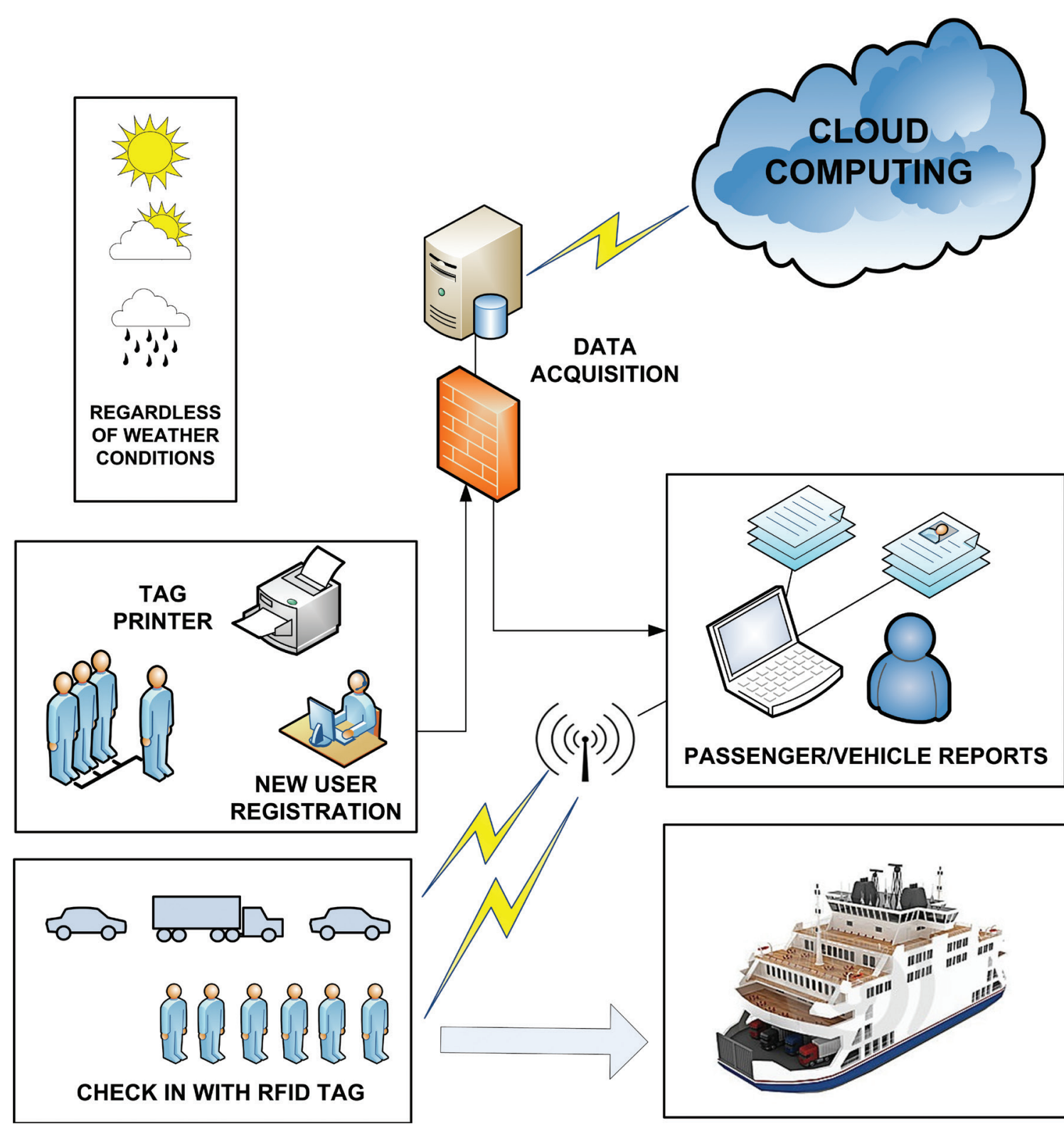

Figure 6.

Embarkation of passengers and vehicles supported by RFID technology. 
The RFID check-in procedure can be performed regardless of weather conditions, making the entire process more robust and reliable. Tags can be interrogated either by RFID handheld (mobile) readers or more complex stationary readers. Stationary RFID readers can be placed at various locations onboard ships and in ports: at entry/exit terminals, at locations of container transshipment from terminal - to ship and vice versa, on machinery used at the terminal or at any other location requiring automatic identification.

The entire tag check-in process unfolds without additionally burdening employees, and thus directly minimizing the possibility of human error. After testing each tag attribute, the application generates a text message and sends it to the user. The application processes the collected data and sends them in the appropriate digital format to the assigned database. The collected data can be stored on a local database server (agency), on a maritime company's database server, or, more reliably, in the cloud (Ristov et al., 2015).

RFID technology is capable of significantly improving security due to the ability of the system software (using increment and decrement variables of embarked and disembarked people) to establish, at any moment, exactly how many people (passengers and crew) had left the ship or remained onboard in case of fire or any other danger requiring evacuation. The RFID system provides real time insight into the precise current locations of the remaining people onboard. Its ability to offer information on the last location and last time when a particular tag was read makes it invaluable in case of a missing person (or man overboard situation), since these are very important clues in any search and rescue operation. Therefore, the authors recommend the use of bracelet tags instead of card tags.

Storing data in the cloud is an easy, reliable and automated backup mechanism for real time data storage to a remote location. Furthermore, this mechanism provides very efficient compression, global data deduplication, significantly reducing storage timeframe, etc.

\subsection{Model of Access Control Supported by RFID Technology}

Process Modeler 5 for Microsoft Visio allows the creation of BPMN (Business Process Modeling Notation) diagrams in compliance with the BPMN 1.0 specification, with all elements and all attributes defined in the above specification. Figure 7 illustrates the model of processes of a RFID access control system for the embarkation of passengers and vehicles on ferries.

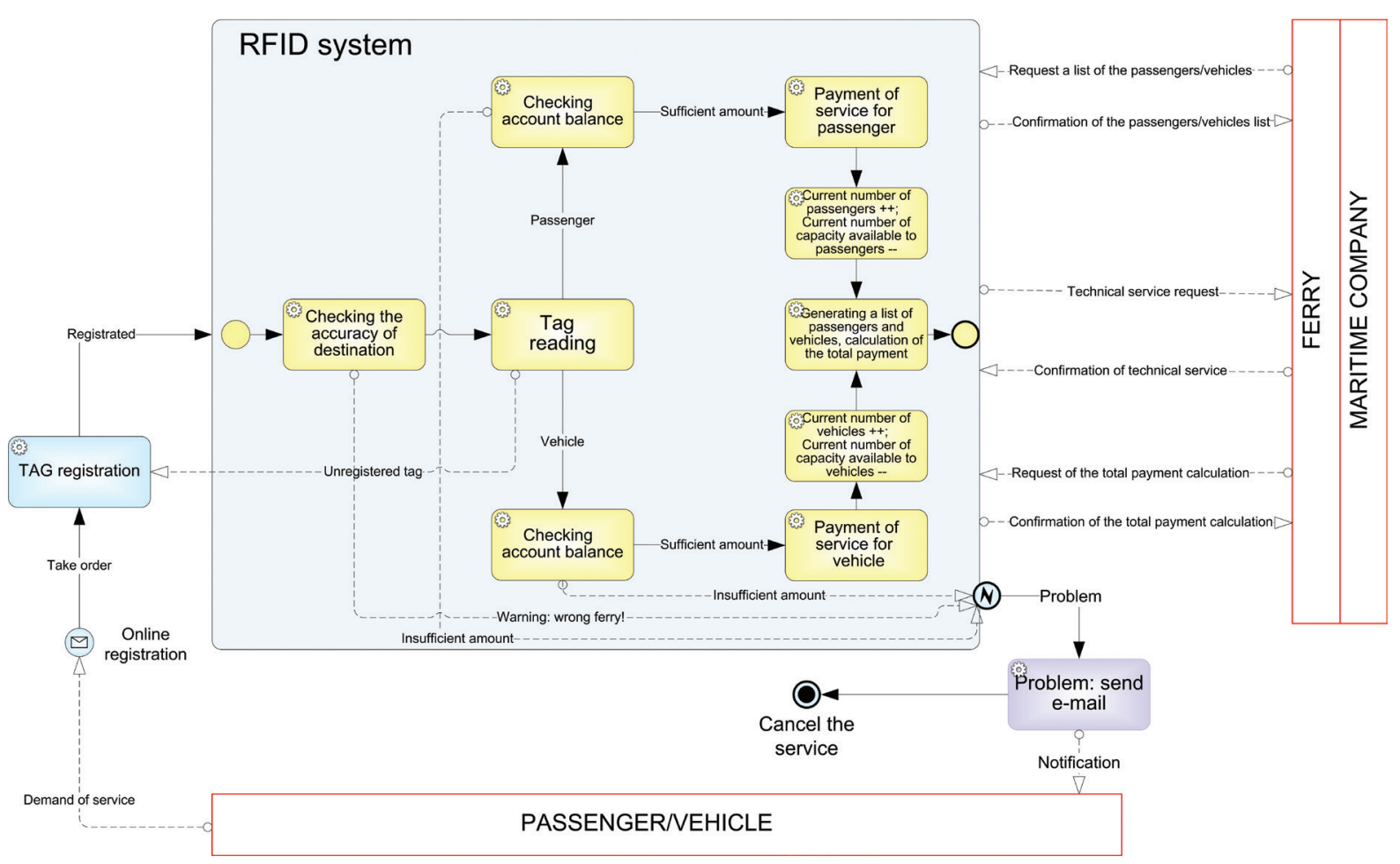

Figure 7.

Model of RFID access control system processes. 
The above model of RFID access control system processes clearly demonstrates the substantial contribution and possibilities of RFID systems in terms of embarkation of passengers and vehicles on ferries. Tags need to be registered in the database prior to the beginning of embarkation. The validity of a tag is checked once embarkation begins. If the system determines that a tag is not registered, the user will be informed thereof and prevented from boarding the ship. On the other hand, if a user has a properly registered tag, the RFID system starts to collect and process data from the tag, and thus initiates the embarkation procedure. The first step of the system is to check whether the user is boarding the correct ferry by comparing port of destination indicated in the user's tag with the port of destination of the respective ferry. This important step can help preventing misunderstandings and boarding of wrong ferry lines. This algorithm is of special importance for foreign tourists who are unfamiliar with the layout of berths in the port. The RFID system then proceeds to determine whether the detected tag is registered as a passenger or as a vehicle. The next step is the automatic establishment of balance on the account, followed by charging the correct amount for the transportation of passengers or vehicles. Once the payment is made, the condition of counter variables in the RFID system is changed and thus separately calculated for passengers and vehicles. The variable of the current number of passengers/ vehicles is initially set to zero, while the variable of available passenger/vehicle capacity is initially equal to the actual physical passenger/vehicle capacity of the ferry. By simply increasing the variable of the current number of passengers/vehicles, while simultaneously decreasing the variable of available passenger/ vehicle capacity, the RFID system can, at any moment, calculate current capacity. Since passenger/vehicle capacity of the ferry is initially a constant corresponding to the actual capacity of that ferry, defined in its technical characteristic during construction, the sum of the variable of the current capacity occupied by passengers/vehicles and the variable of available passenger/ vehicle capacity must necessarily, at all times, correspond to the actual physical capacity of the respective ferry. A clear indication of vehicle type on tags is necessary and should be used to distinguish cars from trucks to ensure adequate space on the ferry. Finally, following the end of the embarkation process, the RFID system automatically generates a report on passengers and vehicles, and calculates the total amount of payments and the profit of the respective voyage. During embarkation, the maritime company/agency and the ship's captain have constant access to and automatic communication with the RFID system in real time, thus ensuring consistent enforcement of business policies.

Following the analysis of embarkation processes, an electronic circuit and its respective software were created to test the basic possibilities of the RFID system. Multiplicative passive smart cards were used to test the system. The advantage of using
RFID cards is that each user has a single card (tag) that can be used multiple times over a number of years. This advantage is especially important for tourists who return every year. Only an authorized person can change the information stored on the card (tag). Data change devices are located at several locations in the port and/or at an authorized agency. RFID access control by means of smart cards is compliant with the ISO/IEC 14443 standard. When it comes to reading passive tags, the recommendation is to take the optimum distance between reader and tag into account. Reading can be performed at distances deviating from the optimum distance, but this reduces bandwidth and sampling rate.

Figure 8 is an overview of an entire RFID system, including a central computer with software support.

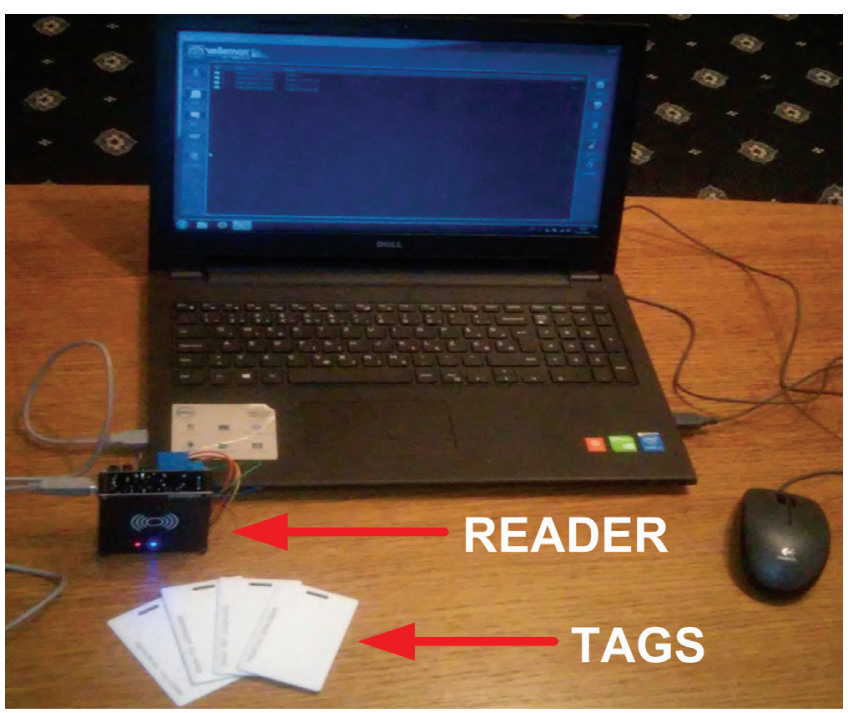

Figure 8.

Overview of a RFID system.

Access control system based on RFID technology is managed by software support installed on a central computer. Proper software use allows:

- registration of new tags in a database stored on the central computer or their storage directly in the reader's memory,

- determination of access rights and authorities,

- $\quad$ entering of data into tag's memory and subsequent reading thereof,

- $\quad$ entering of desired tag attributes,

- master card setting,

- deletion of old or creation of a new database,

- deletion of a particular tag from the database or complete deletion of the system's memory.

The main features of the suggested tag for access control in the process of passenger and vehicle embarkation are: 
- passenger code,

- vehicle code (e.g. license plate) and indication of vehicle type (car or truck),

- maritime company code,

- ticket code,

- account balance,

- date and time of transaction,

- ferry line code and berth number (to check port of destination),

- $\quad$ name and surname of passenger or vehicle owner.

The introduction of RFID technology as a substitute for conventional paper tickets and cash payments resulted in the acceleration of payment services. Table 2 indicates the outcomes of testing of different payment services reported in literature (Czako, 1997).

Table 2.

Acceleration of payment services by RFID technology (Czako, 1997).

\section{Technology}

Passenger processing time

RFID tags with greater reading $\quad 1.7$

distances

\begin{tabular}{lc|}
\hline $\begin{array}{l}\text { RFID tags with smaller reading } \\
\text { distances }\end{array}$ & 2.5 \\
\hline Contact smart card & 3.5 \\
\hline Cash payment & $>6$ \\
\hline
\end{tabular}

The software used ensures the transparency of input records, allows the sorting and selection of desired characteristics and generation of reports such as:

- crew list,

- passengers list,

- vehicle number and types,

- individual and summary reports on the number of passengers and vehicles on each ship,

- individual and summary reports on the number of passengers and vehicles at every destination,

- individual and summary reports on the number of passengers and vehicles transported by a specific shipping company,

- etc.

\section{CONCLUSION}

RFID technology is a suitable identification and automatic data collection tool. In the global business world RFID technology can be used to redesign the existing port processes, cut costs and raise operational efficiency by improving factors such as efficiency, accuracy, transparency and security.

The greatest advantage of RFID technology is that it allows readers to simultaneously read multiple tags, providing appropriate anti-collision procedures are applied, which leads to significant time savings. This feature makes RFID the most suitable technology for the control of the embarkation of passengers/vehicles on ferries. The paper gives an example of the application of an anti-collision procedure to prevent interference among tags, which increased passenger and vehicle flow rates.

Rapid and precise information acquisition is achieved by recording each passenger and vehicle with a tag, ensuring efficient tracing of passengers and vehicles in real time, as well as identification of their point of embarkation/disembarkation, etc. Apart from container traffic control and monitoring, RFID technology has the potential to replace conventional paper ferry tickets. This paper provides an extensive description of the potential of the RFID system for passenger and vehicle access control during embarkation. Proper use of RFID technology automates port processes and improves business management by reducing workload and eliminating the possibility of human error.

\section{REFERENCES}

Czako, J., (1997), Neue Innovationsplattform fur Verkehrsunternehmen. Berlin: Tagungsband.

EPCGlobal, http://www.gs1.org/epcglobal/, [accessed 09 September 2015.].

Finkenzeller, K., (2010), RFID handbook, 3rd edition, pp. 194 - 211., New York: John Wiley and Sons, Ltd.

Günther, O., Kletti, W. and Kubach, U., (2008), RFID in Manufacturing, BerlinHeidelberg: Springer-Verlag.

Hansen, W-R., Gillert, F., Cox, K. and Schmid, V., (2006), RFID for the Optimization of Business Processes, pp. 221-256., New York: JohnWiley\&Sons Ltd.

Narsoo, J., Muslun, W. and Sunhaloo, M. S., (2009), A Radio-frequency identification (RFID) Container Tracking System for Port Louis Harbor: The Case of Mauritius, Issues in Informing Science and Information Technology, X(2009), pp. 127 - 142., available at: http://iisit.org/Vol6/IISITv6p127-142Nars00691.pdf, [accessed 10 December 2015.].

Research reports and subscriptions, http://www.idtechex.com/reports, [accessed 18 December 2015.]. 
Ristov, P. and Mrvica, A., (2011), Primjena RFID tehnologije u pomorstvu, Proc. of 3th International Maritime Science Conference, Split, Croatia, May 21, pp. 247 - 259., available at: https://www.pfst.unist.hr/imsc/archive/2011/IMSC2011_Proceedings. pdf, [accessed 16 December 2015.]

Ristov, P., Mrvica, A. and Mišković, T., (2015), RFID based access control system, Proc. of 38th International Convention, MIPRO, Pula, Croatia, May 25 - 29, pp. 1793-1798., available at: http://docs.mipro-proceedings.com/deglgps/DEGLGPS_10_3257.pdf, [accessed 17 December 2015.].

RFID, http://www.gs1 hr.org/djelatnosti/prikupljanje/rfid, [accessed 12 September 2015.].

Swedberg, C., (2013), Fjord Line Puts RFID Aboard Ferry, RFID Journal, available at: http://www.rfidjournal.com/articles/pdf?11087, [accessed 15 December 2015.].
Swedberg, C., (2010), World's Largest Cruise Ship Launches RFID based PassengerTracking System, RFID Journal, available at: http://www.rfidjournal.com/articles/ pdf?7415, [accessed 16 December 2015.].

Swedberg, C., (2014), RFID Sets Sail With Quantum of the Seas, RFID Journal, available at: http://www.rfidjournal.com/articles/pdf?12380, [accessed 16 December 2015.]

Usama S. and Mohammed, M-S., (2011), Tag Anti-collision Algorithm for RFID Systems with Minimum Overhead Information in the Identification Process, Radio engineering, 20(1), pp. 61 - 68, available at: http://www.radioeng.cz/ fulltexts/2011/11_01_061_068.pdf, [accessed 10 December 2015.]. 